\title{
The Effect of Food Supplement MalnuForte on the Quality of Life of Children who Suffered Malnutrition in the First 1000 Days of their lives: A Case Report (MalnuForte Case Study)
}

\author{
T.A.J. van Oort ${ }^{1, *}$ and J.M. van Oort ${ }^{2}$ \\ ${ }^{1}$ TO Pharma Consult, Van Lenneplaan 37, 1217 NB Hilversum, The Netherlands \\ ${ }^{2}$ JvO Health Consultancy, Gerardus Gullaan 16, 1217 LN Hilversum, The Netherlands
}

\begin{abstract}
Objective: Malnutrition is a common worldwide problem and, for children, has a major impact on cognitive and physical development, productivity and health. The damage due to malnutrition is largest when it occurs in the first 1000 days of life. It is largely irreversible and has far-reaching consequences. There is as yet no known cure for the negative effects of malnutrition, while a cure for a large number of previously malnourished children worldwide would lead to better chances for them in life. This case study, therefore, examines the effect of a six-month treatment of MalnuForte on the quality of life of children between 5 and 11 years who suffered malnutrition in the first 1000 days of their lives

Methods: The study subjects are five adopted children who suffered malnutrition in the first 1000 days of their lives and experienced problems or backlog in their quality of life. For six months, the children took one tablet of food supplement MalnuForte a day orally. To estimate the subjects' quality of life, a standardized and validated quality of life questionnaire for children was used, the PedsQL.

Results: A higher quality of life after six months was found for all subjects. The mean total increase of the PedsQL scores between baseline and 6 months was $50 \%$.

Conclusion: In this case study, the intake of food supplement MalnuForte shows remarkable increases in the quality of life of five adopted children who had suffered from malnutrition during the first 1000 days of their lives.
\end{abstract}

Keywords: Malnutrition, intervention, damage, cure.

\section{INTRODUCTION}

Malnutrition is a common worldwide problem, especially in developing countries where approximately $15 \%$ of the population is malnourished [1]. It has a major impact on cognitive and physical development, productivity and health [2]. The damage due to malnutrition is largest when it occurs in the first 1000 days of life, from conception to 24 months of age. It is largely irreversible and has far-reaching consequences that often remain invisible until it is too late [3].

These first 1000 days of life are critical for cognitive development [4]. The foundation of sensory and perceptual systems that underlie language and socioemotional behaviour are formed in this period. Disruption of brain development during these critical 1000 days leads to low cognitive development. Cognitive competence in the first years of life is a predictor of this competence later in life [5]. This means that low cognitive development impacts performance at school in later childhood and adolescence. This contributes to educational and economic consequences at individual, household and community levels [3]. Consequently, a future decrease in income

*Address correspondence to this author at the TO Pharma Consult, Van Lenneplaan 37, 1217 NB Hilversum, The Netherlands; E-mail: tvo@planet.nl

E-ISSN: 1929-4247/19 of up to $22 \%$ globally is seen, which again results in women giving birth to babies with low birth weight [6]. This shows that the damage at very early childhood results in a lifelong cycle of poor nutrition, illness, poverty and inequity.

At the moment, attention is especially given to preventive actions against malnutrition, such as investing in a better start of life. However, no cure for the negative effects of malnutrition exists yet $[7,8]$. While prevention is indeed very important in this matter, finding a cure for the large numbers of previously malnourished children worldwide is also of vital importance. Healing those children leads to better chances for them in life and can even result in breaking the vicious circle of poor nutrition, illness, poverty and inequity. This case study, therefore, examines the effect of a possible treatment for the damage incurred in children who suffered malnutrition in the first 1000 days of their lives. This case study aimed to study the effect of food supplement MalnuForte after six months on the quality of life of five children who had suffered from malnutrition in the first 1000 days of their lives.

\section{MATERIALS AND METHODS}

\section{Design}

This case study examines the effect of food supplement MalnuForte after six months on the quality 
Table 1: Details about the Subjects

\begin{tabular}{|c|c|c|c|c|}
\hline Subject number & Country of origin & Malnourishment in the past & Age at adoption & Age at inclusion \\
\hline \hline 1 & Lesotho & Severe malnourishment until 1 year & 4.5 & 8 \\
\hline 2 & Lesotho & Malnourishment until 5 years & 5.5 & 9 \\
\hline 3 & Lesotho & $\begin{array}{c}\text { Severe malnourishment until 1 year } \\
\text { and 7 months }\end{array}$ & 1.5 & 5 \\
\hline 4 & Haiti & Malnourishment until 1 year & 3.75 & 11 \\
\hline 5 & South Africa & Severe malnourishment until 3 years & 7.5 & Female \\
\hline
\end{tabular}

of life of children who suffered from malnutrition in the first 1000 days of their lives.

\section{Subjects}

The subjects in this case study consisted of five adopted children between five and eleven years old who had suffered from malnutrition during the first 1000 days of their lives and experienced problems or backlog in their quality of life, scoring 75 points or less on the PedsQL scale at inclusion. All subjects had no longer been malnourished for at least three years before inclusion in the study. Since no cut-off point on the PedsQL scale is available for malnourished children, we chose a cut-off point well below the one for healthy children. An average of $86-90$ points, depending on age below 8 or above 8 , is measured for healthy children according to the literature [9]. The subjects participated in the study between May 2018 and April 2019 in The Netherlands. Details are shown in Table 1.

\section{Intervention}

During a time span of six months, the children took one tablet of food supplement MalnuForte before breakfast orally. The MalnuForte tablet contains $19 \mathrm{mg}$ of a mixture of calcium carbonate- and calcium hydrogen phosphate-substances and it contains lactose as an excipient. The mineral substances and the excipient are harmless according to safety data [1012]. Accountability of the food supplement intake was managed by the close contact of the study team with the subjects and their mother.

\section{Data Collection}

To estimate the study outcome about the quality of life, a standardized and validated quality of life questionnaire for children was used, the Dutch version of the PedsQL designed by James W. Varni, PhD [13]. This questionnaire contains a total of 23 questions split up in four sections. It contains 8 questions about physical functioning, 5 about emotional functioning, 5 about social functioning and 5 about school functioning. A general quality of life score can be created by including all four sections; a physical health summary score by only including the section physical functioning; and a psychosocial health summary score by including the three sections emotional functioning, social functioning and school functioning. All three types of scores are used in this study. The questionnaire has a 0-4 scale, in which 0 means no problems concerning the question and 4 means a maximum of problems concerning the question. The 0-4 scale must be transformed to a $0-100$ scale as follows: $0=100,1=75$, $2=50,3=25$ or $4=0$ points. Scores are calculated by dividing the total number of points by the number of questions answered. The maximum possible total score on the questionnaire is 100 and can be interpreted as a perfect quality of life; the minimum possible score is 0 and can be interpreted as very poor quality of life. The questionnaire has good reliability (alpha between 0.83 and 0.99 ) and good validity and is applicable in clinical trials $[14,15]$.

During the research period, one parent observed the child and completed the PedsQL questionnaire at baseline and after six months to estimate the outcome. See Figure 1 for a visual research scheme. The parents of the children gave informed consent and the children gave informed assent before participating in this case study.

\section{RESULTS}

\section{Outcomes}

A higher quality of life after six months was found for all subjects. Increases in the PedsQL scores are seen on all three types of scores, namely on the general quality of life score by an average of $50 \%$, the physical health summary score by an average of $43 \%$ and the psychosocial health summary score by an 


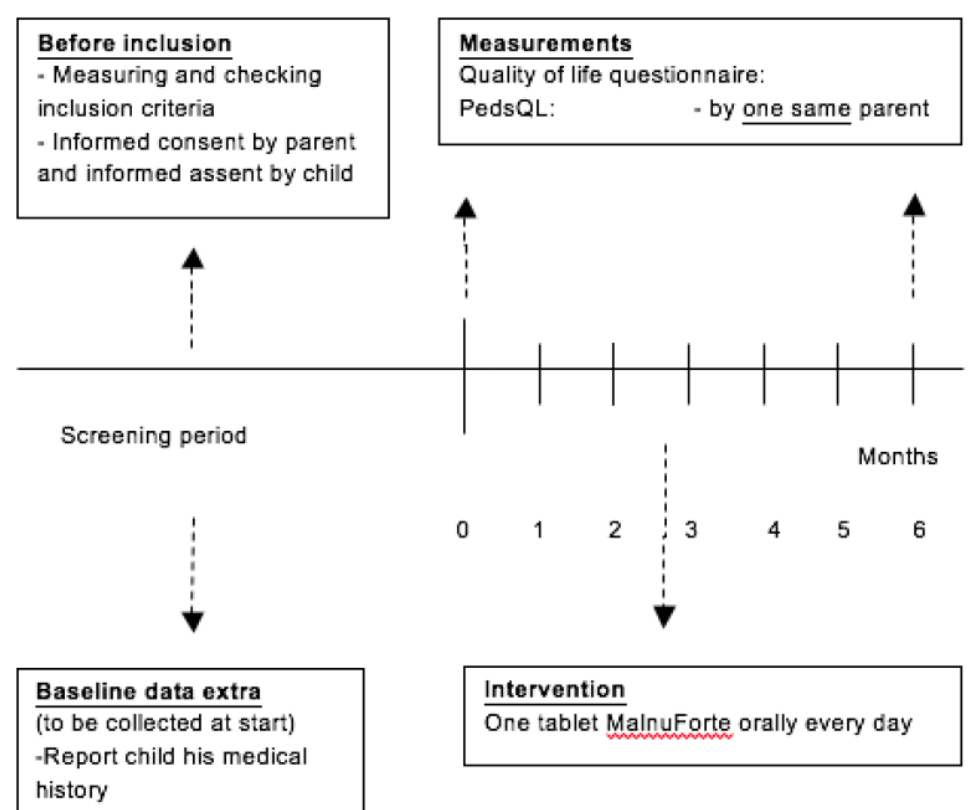

Figure 1: Visual research scheme.

average of $54 \%$. The general quality of life score increased between baseline and 6 months from 41 to 74,50 to 76,71 to 97,54 to 79 and 64 to 86 points; $79 \%, 52 \%, 37 \%, 46 \%$ and $34 \%$ respectively for the five subjects as seen in Figures 2 and 3. After splitting up for physical health summary score and psychosocial health summary score, we found increases for physical health summary scores from 53 to 91,59 to 91,84 to 100,56 to 75 and 66 to 91 points for the five subjects; $71 \%, 53 \%, 19 \%, 33 \%$ and $38 \%$ respectively as seen in Figures 4 and 5. Psychosocial health summary scores increased from 35 to 65,45 to 68,63 to 95,53 to 82 and 63 to 83 points for the five subjects; $86 \%, 52 \%$, $50 \%, 53 \%$ and $32 \%$ respectively as seen in Figures 6 and 7 .

\section{DISCUSSION}

In this case study, the intake of food supplement MalnuForte showed remarkable increases in the quality of life of five adopted children who had suffered from malnutrition during the first 1000 days of their lives.

A strength of this study is the completion of the questionnaire by the mother. As is commonly reported in the literature, this gives a very reliable outcome, since the mother sees the child every day and knows the best [9]. Besides, the motivation to participate in the study because of the children's backlog in quality of life increases the intervention adherence. Furthermore, the study team kept in close contact with the children's mothers to monitor progress over time. However, the mothers' hope to see an improvement and their knowledge of the intervention is a potential source of bias.

The mechanism of action of MalnuForte is not yet known, which is a limitation of the study. The subjects included all suffered malnutrition during the first 1000 days of their lives. However, the exact malnourished

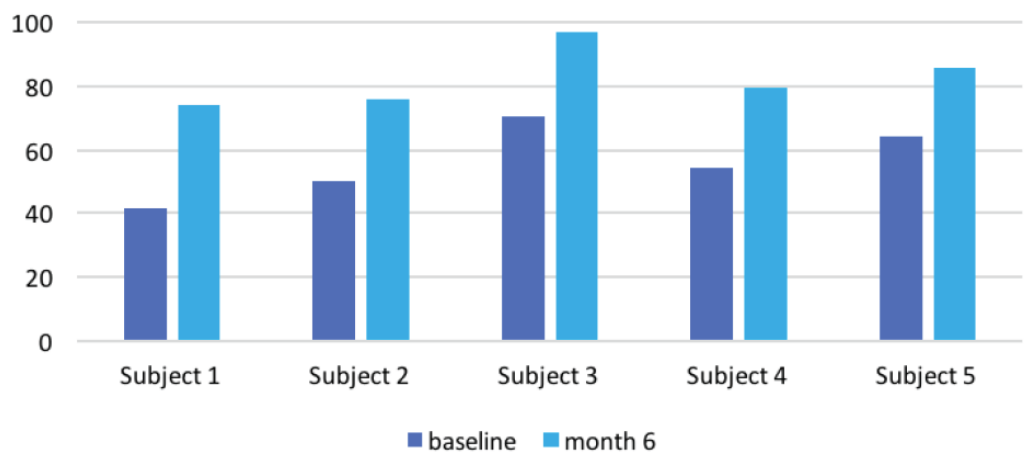

Figure 2: General quality of life score at baseline and month 6 . 


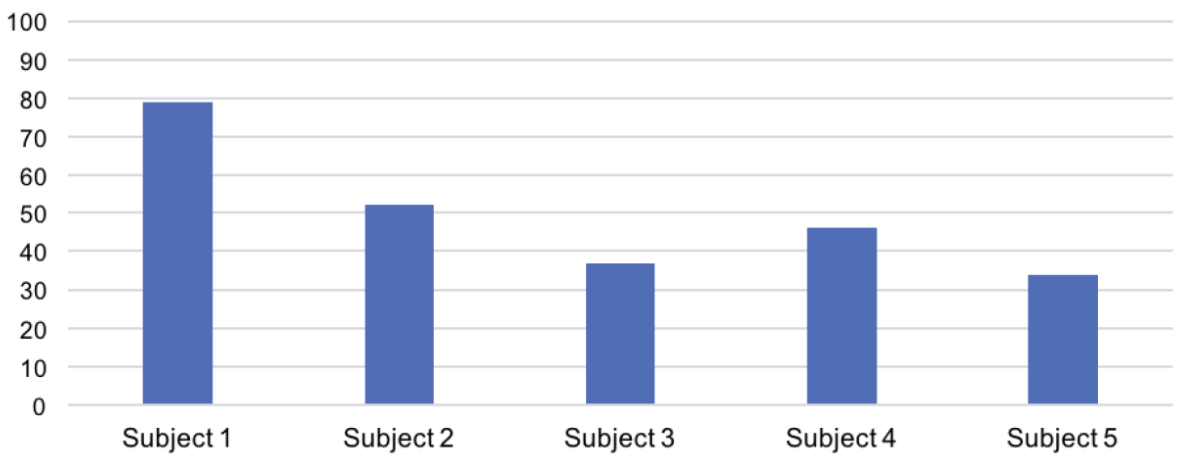

Figure 3: General quality of life score: \% score increase at baseline and month 6 .

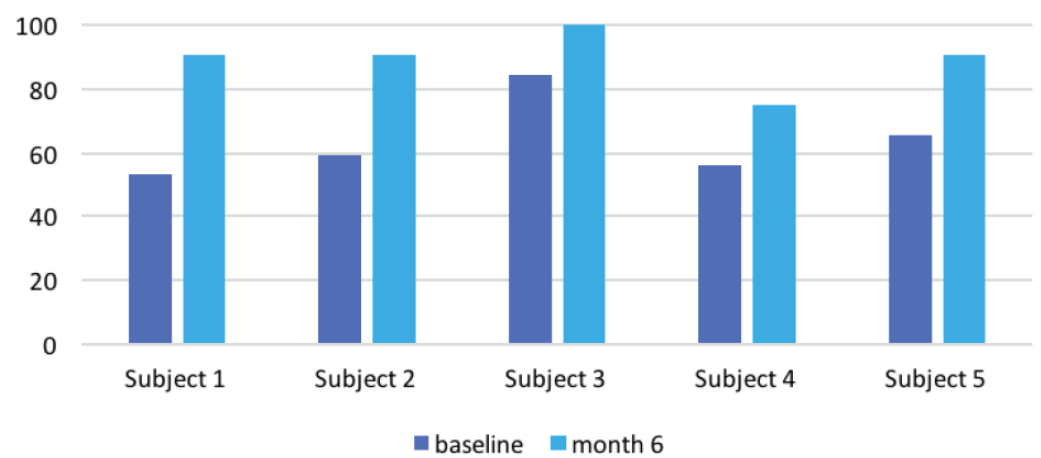

Figure 4: Physical health summary score at baseline and month 6.

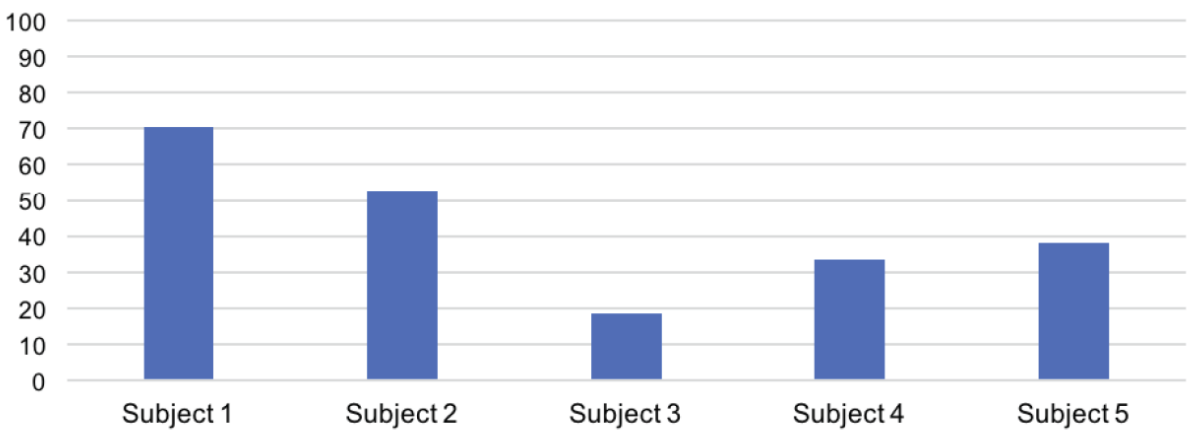

Figure 5: Physical health summary score: \% score increase at baseline and month 6 .

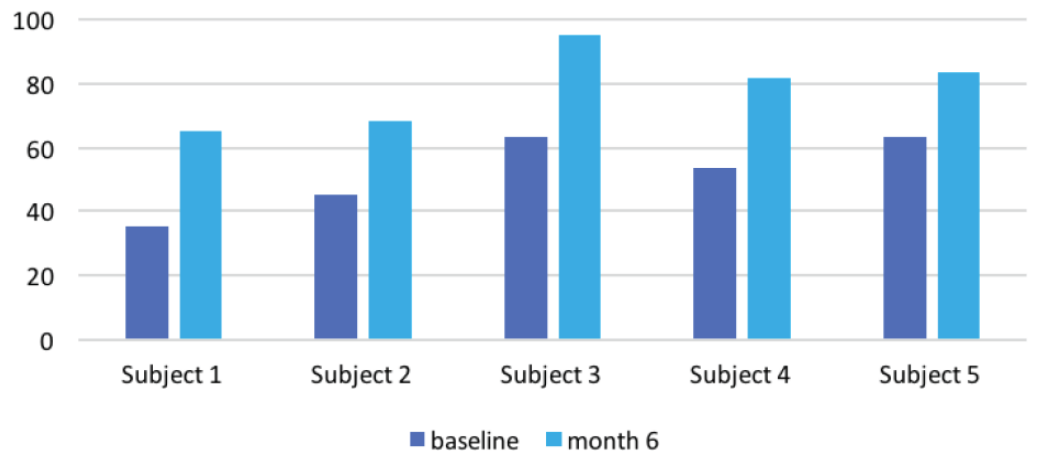

Figure 6: Psychosocial health summary score at baseline and month 6. 


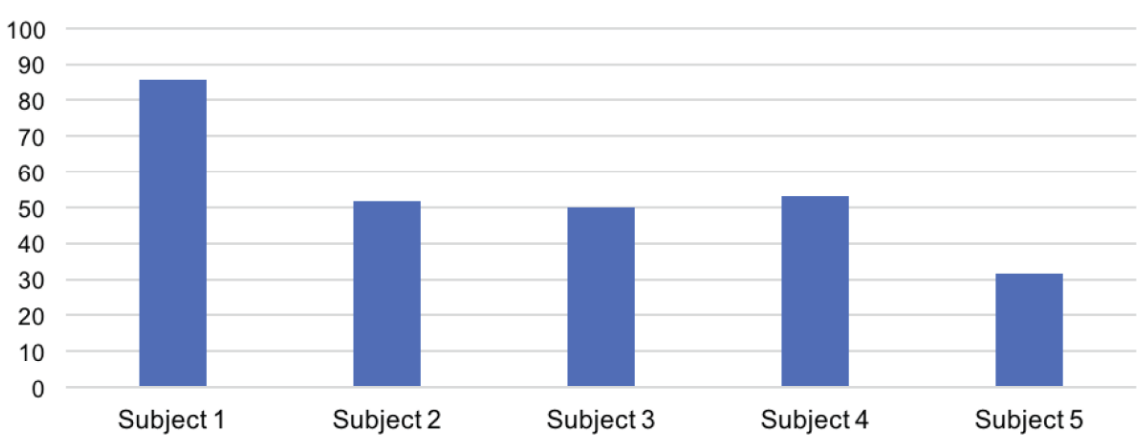

Figure 7: Psychosocial health summary score: \% score increase at baseline and month 6.

status was hard to estimate due to a lack of data, because the children were adopted and lived mostly on the streets during these 1000 days. This is also a limitation of the study. Only a small number of children were included, which is inherent to a case study and means only tentative assumptions can be drawn from the data obtained.

In summary, previous literature shows that there is as yet no cure for the negative effects sustained due to malnutrition in the first 1000 days of life $[7,8]$. However, a cure for a large number of children already affected worldwide is of vital importance to heal those children, improve their chances in life and possibly even break the vicious circle of poor nutrition, illness, poverty and inequity. To obtain this, we studied the effect of food supplement MalnuForte on the quality of life in children who had been malnourished early in life and found promising results. These results warrant additional research in the form of a randomised placebo-controlled trial to further study the effect of food supplement MalnuForte on children's quality of life after having been malnourished in the first 1000 days of life.

\section{CONCLUSION}

In this case study, the intake of food supplement MalnuForte showed remarkable increases in the quality of life of five adopted children who had suffered from malnutrition during the first 1000 days of their lives.

\section{ACKNOWLEDGEMENTS}

We would like to thank Prof. Dr. D.E. Grobbee for his input and feedback on the trial design and this manuscript.

\section{DISCLOSURE}

The authors declare no conflict of interest.

\section{REFERENCES}

[1] World Food Programme. Hunger Statistics [Internet]. 2018 [cited 2018 Dec 15]. Available from: https://www.wfp.org/ hunger/stats

[2] UNICEF. Nutrition Introduction [Internet]. 2018 [cited 2018 Dec 15]. Available from: http://www.unicef.org/nutrition/

[3] World Health Organization. Weise A. WHA Global Nutrition Targets 2025: Stunting Policy Brief. 2014; Available from: http://www.who.int/nutrition/topics/globaltargets_stunting_poli cybrief.pdf

[4] Knickmeyer RC, Gouttard S, Kang C, Evans D, Wilber K, Smith JK, et al. A structural MRI study of human brain development from birth to 2 years. J Neurosci 2008; 28: 12176-28. https://doi.org/10.1523/JNEUROSCI.3479-08.2008

[5] Rose SA, Feldman JF, Futterweit LR, Jankowski JJ. Continuity in tactual- visual cross-modal transfer: infancy to 11 years. Dev Psychol 1998; 34: 435-40. https://doi.org/10.1037/0012-1649.34.3.435

[6] UNICEF. Improving child nutrition: The achievable imperative for global progress. [Internet]. 2013. Available from: https://www.unicef.org/gambia/Improving_Child_Nutrition__the_achievable_imperative_for_global_progress.pdf

[7] Ashworth A. Efficacy and effectiveness of community-based treatment of severe malnutrition. Food Nutr Bull 2006; 27(3 Suppl): S24-48. https://doi.org/10.1177/15648265060273S303

[8] Picot J, Hartwell D, Harris P, Mendes D, Clegg AJ, Takeda A The effectiveness of interventions to treat severe acute malnutrition in young children: a systematic review. Health Technol Assess [Internet]. 2012; 16(19): 1-316. https://doi.org/10.3310/hta16190

[9] Huang IC, Thompson LA, Chi YY, Knapp CA, Revicki DA Seid $M$, et al. The linkage between pediatric quality of life and health conditions: establishing clinically meaningful cutoff scores for the PedsQL. Value Health [Internet] 12(5): 773-81.

https://doi.org/10.1111/j.1524-4733.2008.00487.x

[10] National Institutes of Health. Calcium fact sheet for health professionals. 2018; Available from: https://ods.od.nih.gov/ factsheets/Calcium-HealthProfessional/

[11] EFSA Journal. Scientific Opinion on Dietary Reference Values for phosphorus1 [Internet]. 2014 [cited 2019 Feb 26]. Available from: http://www.efsa.europa.eu/sites/default/ files/consultation/150310b.pdf

[12] EFSA Journal. Scientific Opinion on re-evaluation of calcium carbonate (E 170) as a food additive1. EFSA J [Internet] 2011; 9(7). https://doi.org/10.2903/j.efsa.2011.2318

[13] Varni JW. PedsQL [Internet]. 2019. Available from: https://www.pedsql.org 
[14] Varni JW, Seid M, Kurtin PS. PedsQL 4.0: reliability and validity of the Pediatric Quality of Life Inventory version 4.0 generic core scales in healthy and patient populations. Med Care 2001; 39(8): 800-12.

https://doi.org/10.1097/00005650-200108000-00006

[15] Desai AD, Zhou C, Stanford S, Haaland W. Validity and responsiveness of the pediatric quality of life inventory
(PedsQL) 4.0 generic core scales in the pediatric inpatient setting. JAMA Pediatr 168(12): 1114-21.

https://doi.org/10.1001/jamapediatrics.2014.1600

[16] UNICEF. Malnutrition [Internet]. 2019 [cited 2019 Apr 22]. Available from: http://data.unicef.org/nutrition/malnutrition. html

https://doi.org/10.6000/1929-4247.2019.08.04.1

(C) 2019 Oort and Oort; Licensee Lifescience Global.

This is an open access article licensed under the terms of the Creative Commons Attribution Non-Commercial License (http://creativecommons.org/licenses/by-nc/3.0/) which permits unrestricted, non-commercial use, distribution and reproduction in any medium, provided the work is properly cited. 